\title{
Optimal Design of Ship's Hybrid Power System for Efficient Energy
}

\author{
Maja Krčuma ${ }^{a}$ Anita Gudelja, Vinko Tomas ${ }^{b}$
}

The International Maritime Organization regulations on the reduction of greenhouse gas emissions (GHGs) from ships require efficient dealing with this complex techno-economic and highly political problem through joint efforts of all major stakeholders from the shipbuilding industry and ship operations.

The key problems of any research in the field of renewable energy, including power generation, storage, transformation and distribution, and the issues associated with limited power generation for specific loads, are the same issues that are experienced in the implementation of electric distribution technologies onboard ships.

This paper analyses the effects of efficient shipping using the solar panel system and batteries to ensure continuous power supply, regardless of the weather conditions. The logistics chain of this control architecture is modelled by Colored Petri Nets. The economic analysis examines the annual costs of fuel consumption, the initial capital cost, total net cost and $\mathrm{CO}_{2}$ emissions.

\section{KEY WORDS}

$\sim$ Renewable power

$\sim$ Power management system onboard ships

$\sim$ Energy efficiency

$\sim \mathrm{CO}_{2}$ emissions

$\sim$ Multi-objective optimization

\author{
a. University of Split, Faculty of Maritime Studies, Split, Croatia \\ e-mail: mkrcum@pfst.hr \\ b. University of Rijeka, Faculty of Maritime Studies, Rijeka, Croatia \\ e-mail: tomas@pfri.hr \\ doi: 10.7225/toms.v07.n01.002 \\ This work is licensed under (cc) BY
}

\section{INTRODUCTION}

The Kyoto Protocol of 1997, paragraph 2.2, entrusted the International Maritime Organization (IMO) (3 $3^{\text {rd }}$ IMO GHG Study, 2014) with the responsibility to regulate and reduce harmful emissions from ship (IMO, 2017). Maritime transportation emits approximately 1,000 million tons of $\mathrm{CO}_{2}$ annually and accounts for about $2.5 \%$ of the global greenhouse gas emissions (Kyoto Protocol, 2017). The emissions of harmful contents from vessels are anticipated to increase by $50 \%-250 \%$ by 2050 , depending on the future developments in the fields of economy and energy. This is not in line with the international agreements to decrease global emissions by at least $50 \%$ by 2050 to keep the global temperature increase under $2^{\circ} \mathrm{C}$. The IMO regulated $\mathrm{CO}_{2}$ emissions by adopting Annex VI to the MARPOL Convention. Guidelines for improving energy efficiency were also laid down with the intention to monitor and improve ships' performances and features with regard to various factors that may contribute to $\mathrm{CO}_{2}$ emissions (see Figure 1). A "new" ship means a ship the building contract for which was concluded on or after 1 January 2013 or in the absence of a building contract, the keel of which was laid or which was in the similar stage of construction on or after 1 July 2013 or which was delivered on or after 1 July 2015.

Various studies and papers (Gudelj and Krčum, 2013; EEDI - IMO, 2012; RSSPS, 2017; Øverleir, 2015) indicate that environmental pollution can be significantly reduced and the low energy efficiency of traditional marine systems improved by the proper integration of renewable energy sources onboard vessels where electrical power is produced by the ship's power plant using a diesel / turbo generator.

For instance, the installation of photovoltaic (PV) systems in the power system helps reduce greenhouse gas emissions, improves energy efficiency and contributes to the stability of the ship's power system. 
However, installing a PV system requires significant attention and consideration of certain aspects, such as: unlike land-based systems, onboard power systems are exposed to constant load changes (Krčum et al., 2010). The frequent presence of seawater on the deck, where photovoltaic panels are accommodated, has a significant impact on their effectiveness; at sea, a vessel is always under some load, which may not be the case with shore-based PV systems; while the angle of sunlight at a specific location on land is constantly the same, this is never the case at sea with ever changing waves, sailing routes and courses.

\begin{tabular}{|c|c|c|c|c|}
\hline $2015 \Rightarrow$ & $2020 \Rightarrow$ & $2025 \longrightarrow$ & $2030 \longrightarrow$ & 2050 \\
\hline $\begin{array}{l}\text { Energy } \\
\text { Efficiency } \\
\text { Design } \\
\text { Index-by } \\
\text { "new ship" }\end{array}$ & $\begin{array}{l}\text { Improving } \\
\text { the } \\
\text { efficiency } \\
\text { by } 10 \% \text { - } \\
\text { by "new } \\
\text { ship" }\end{array}$ & $\begin{array}{l}\text { Improving } \\
\text { the } \\
\text { efficiency } \\
\text { by } 20 \% \text { - } \\
\text { by "new } \\
\text { ship" }\end{array}$ & $\begin{array}{l}\text { Improving } \\
\text { the } \\
\text { efficiency } \\
\text { by } 30 \% \text { - } \\
\text { by "new } \\
\text { ship" }\end{array}$ & \\
\hline & & & & $\begin{array}{l}\mathrm{CO}_{2} \\
\text { reduction } \\
\text { by } 50 \% \\
(\mathrm{t} / \mathrm{km})\end{array}$ \\
\hline
\end{tabular}

Figure 1.

IMO recommendations for reducing $\mathrm{CO}_{2}$ emissions 2015-2050

This paper is a contribution to ships' power system energy management in general, and to PLOVPUT's working boat in particular. This vessel, which served as the basis for our research (Tech. doc. PLOVPUT) was under construction. It is a public service workboat, fully equipped to perform a variety of marine and hydro-submarine operations related to the maintenance of waterways in the Croatian Adriatic. These activities include the maintenance of existing and the construction and equipping of new aids to navigation, e.g. marking waterways with navigation buoys; supplying and maintaining onshore and offshore lighthouses; transportation and installation of construction materials onshore and under the sea, performing hydrosubmarine operations; transportation of construction machinery.

The vessels' energy resources include:

- Three main-board voltage generators: diesel electric power generators $190 \mathrm{kVA}, 3 \times 400 \mathrm{~V}, 50 \mathrm{~Hz}$, one diesel electric generator $80 \mathrm{kVA}, 3 \times 400 \mathrm{~V}, 50 \mathrm{~Hz}$ and an inverter/charger; and

- Secondary-board voltage transformer, batteries and rectifiers.

The diesel electric aggregate (DEA) meets energy consumption needs in all modes, depending on the balance of electricity. In the operating mode and normal mode of navigation, all required power is provided by one diesel electric aggregate (1x190 kVA). In departure mode, buoy handling mode and concrete plant operation mode, the required power is supplied by two DEA (2x190 kVA) in parallel operation. When staying in port, electricity supply is provided by one DEA due to reduced electricity consumption. In case of overload, the power management system shuts down shedable, i.e. less important consumers.

The authors of this study assume that the integration of renewable energy sources in the vessel's power system (Figure 2) may contribute to $\mathrm{CO}_{2}$ emission reduction. The basis for this hypothesis were the results obtained by the simulation of a hybrid marine power system on HOGA software, developed on the basis of Colored Petri Nets (CPN) models that coordinate and manage the flow of information.

\section{POWER MANAGEMENT IN THE PROPOSED SHIP'S POWER PLANT}

Figure 2 shows the hybrid system consisting of PV panels, batteries, a charge regulator, AC diesel generators, converters/ inverters, and load controls. The hybrid power distributed generation system provides four operating modes, depending on the prevailing environmental conditions, battery charge status and load variation. The controller switches from one mode to another, depending on instructions determining mode selection.

Mode 0: If solar energy is not available and the state of charge $(S O C)$ of the batteries is very low, i.e. lower than the minimum recommended by the manufacturer (SOCmin), the batteries should not be used and the required energy should be provided by the AC generator.

Mode 1: If weather is cloudy and (SOC) is normal, the controller allows the batteries to provide sufficient power for the load. If the load exceeds the power of batteries, excess load will be handled by the AC generator. This mode is maintained while the state of charge $(\mathrm{SOC})$ is above SOCmin or while power obtained from solar energy is above threshold power. Outside the above limits, the hybrid power system must switch either to Mode 0 or Mode 2.

Mode 2: If there is plenty of solar energy, photovoltaic $(P V)$ system resources are connected to the vessel's grid and PV-generated energy must be preferentially used to power the loads. In the event of surplus energy (Pch), the controller puts the batteries into charging mode until they reach maximum charge value (SOCmax). If the power supplied by the PV system is insufficient for the load, the necessary power should be supplied by the batteries.

If the batteries cannot handle the entire load, the excess part of the load will be handled by the AC generator.

Mode 3: In this mode the load demand (Pload) is lower than the available solar energy ( $P p v)$ and the batteries are fully charged (SOC $>=S O C$ max). This mode is used when there is sufficient PV power to meet the total demand and it is maintained until the load exceeds the available PV power. If the total load exceeds the available PV power, the system switches to Mode 1. 


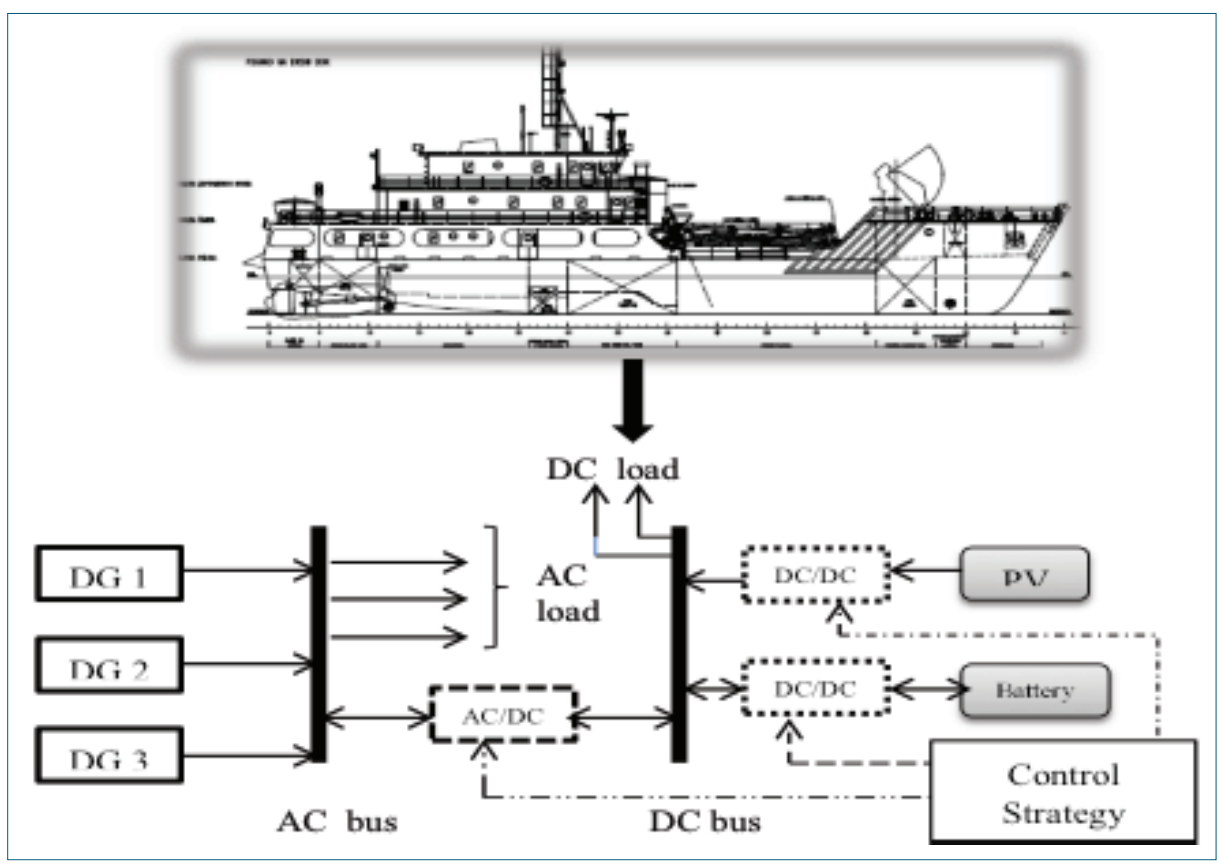

Figure 2.

Hybrid ship power system configuration.

For modes 1, 2 and 3, if the AC generator produces more power than required, and the power envisaged to be supplied by the AC generator is lower than the critical power limit (Pcritical_ gen), surplus power can be used to charge the batteries up to SOC value, the so-called SOCstp_gen (batteries SOC set point for the AC generator). In order to present a supervising control of the hybrid energy system, the following sections discuss the use of Colored Petri Nets (CPNs). Since the hybrid renewable energy system consists of several sources and involves different states and events, the entire system is considered to be a discrete event system (DES). The discrete dynamics of power systems are particularly relevant for mode switching and selecting sources on $D C$ and $A C$ buses depending on the available renewable energy and load. CPNs allow us to define which actions occur in DES, which states preceded these actions and which states will be achieved after the actions have been performed. Colored Petri Nets is an outstanding tool for testing the simulated environment and avoiding the occurrence of potential forbidden states in the real world.

\subsection{Colored Petri Nets (CPNs)}

Petri net (PN) is a bipartite graph determined by four kinds of objects: places, transitions, directed arcs and tokens (Gudelj et al., 2012). In the PN model, places represent system states and transitions represent the assessment of transition of system states. Colored Petri Net (CPN) combines the best of classical PNs and high level programming languages (Jensen et al., 2007; Jensen, 1991). Data, data types and transition conditions are described by a functional programming language. The token, with attached data value (called token color), can encode a vast amount of information that determines transition firing. Places are associated with color sets. A color set specifies the data type a place can hold. A transition can be programmed using special constructs and functions. Additional constructs can be used to enable or disable transition firing. Input and output arcs can have expressions and functions related to them. For a transition to be enabled, input arcs expressions need to bind successfully with the tokens present in the input places and the transition guard. The tokens are placed in the respective output places.

A Colored Petri Net can be formally defined as a 9-tuple (Jensen, 1991).

$C P N=\left(P, T, A, \Sigma, N, C, G, E, m_{0}\right)$

where, $P$ is a finite set of places, $T$ is a finite set of transitions; $A$ is a finite set of arcs. $\Sigma$ is a finite set of types called color sets. This set contains all possible colors, operations, and functions used within a CPN.

$N: A \rightarrow(P \times T) U(T \times P)$ is a node function. $C$ is a color function which maps places in $P$ into color in $\Sigma$. $G$ is a guard function 
defined from $T$ into guard expressions $g$. The output of the guard expression should evaluate to Boolean value true or false. $E: A \rightarrow[$ expr] is an arc expression function which maps each arc $a \in A$ into expression e. $m_{0}$ is the initial marking of CPN. For more details and CPN theory, refer to (Jensen et al., 2007).

\subsection{CPN Control System}

Based on the proposed hybrid power system (see Introduction) and logistics issues related to the implementation of renewable sources facilitating efficient shipping, algorithms developed by the authors and C-PN rules, we designed a PN model of a control system managing energy flow and

coordinating operations of hybrid energy systems onboard ships (see Figure 3).
The PN controller was designed using CPN tools (Version 4.0.1 (CPNTools, 2017). Taking into account the specific network topology and net load, the model simply focuses on switching modes of operation and estimating the batteries' state of charge (SOC) once an hour. Battery SOC and net load are used as parameters for the ON/OFF control of PV and diesel generators. As stated above, CPN places consist of a set of markers called tokens, with their attached token color. The necessary color sets and variables are as shown in Figure 4. In the design control strategy, hourly intervals are considered, where all the involved variables are assumed to be constant throughout these intervals. Accordingly, the place Next_hour represents one hour which is allocated a single token. Initially this value is 0 , and is updated on an hourly basis.

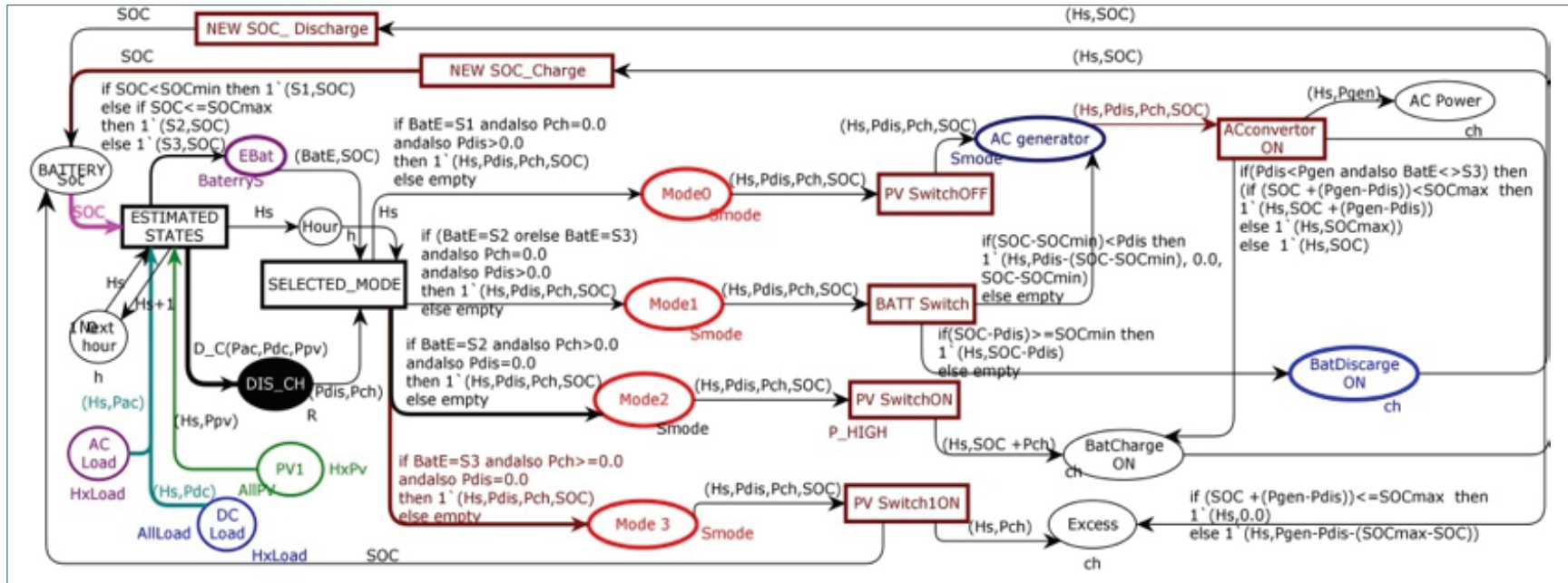

Figure 3.

CPN control design of the ship hybrid energy system.

\begin{tabular}{|c|c|}
\hline 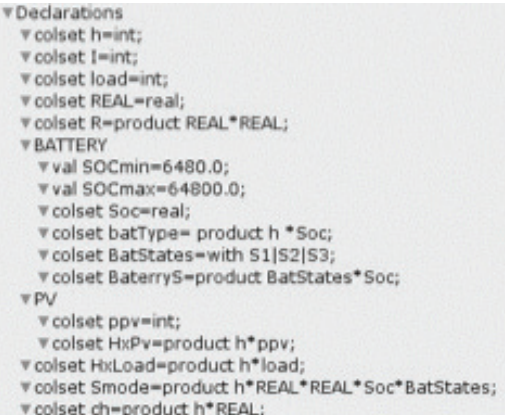 & 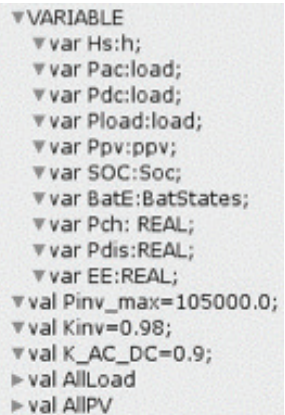 \\
\hline
\end{tabular}

Figure 4

Definition of color sets and variables.
The estimated state of batteries for each hour place is modelled by Ebat. Three states for the batteries are considered and they are defined by three token colors $(\mathrm{S} 1, \mathrm{~S} 2, \mathrm{~S} 3)$ from the colors set batStates (see Figure 3). The first color (S1) indicates that the battery is empty ( $\mathrm{SOC}<\mathrm{SOC}$ min), whereas the second color (S2) signifies that the battery is fully charged. The latter state is reached when the battery state of charge (SOC) becomes equal to or higher than the maximum value (SOCmax). The third color (S3) indicates that the battery is in an intermediate state, i.e. that its SOC is between minimum (SOCmin) and maximum value (SOCmax). The place DIS_CH checks the system energy balance and battery SOC at each time interval and shows whether the system is in Charge state or in Discharge state. Charging and discharging processes are coded by the function Discharge Charge (Figure 5) through a communication link with the load layer and PV resources. 


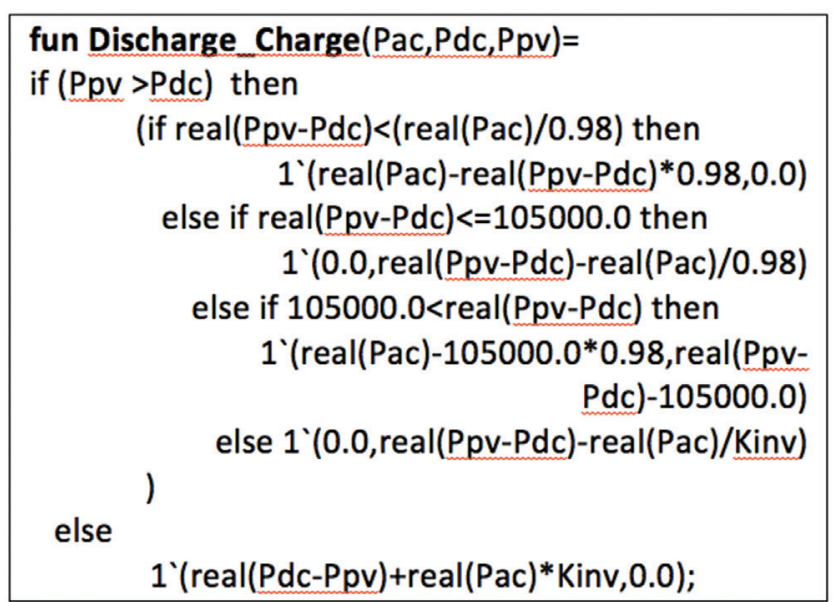

Figure 5.

Function declaration of the CHARGE and DISCHARGE processes.

Pac is power consumed by loads in the AC bus, while Pdc denotes the power consumed by loads in the DC bus. Ppv refers to power produced by $\mathrm{PV}$ renewable sources in the DC bus. $K \_A C / D C$ is the efficiency of the battery charger and Kinv is the efficiency inverter. Pinv_max describes maximum active power that can be produced by the inverter.

This function computes the values of surplus power $(P c h)$ which is used to charge the batteries or the value of the load that has not been fed (Pdis) as a function of the AC load (Pac), the DC load $(P c d)$ and the energy produced by the PV sources Ppv (DufoLopez et al. 2007). If the PV renewable sources produce more energy than required by $A C / D C$, surplus power PCh is calculated on the one-hour basis. If, on the contrary, the PV system is unable to cover DC energy demand $(P p v<P c d)$ or the apparent power at the AC/DC inverter output (PaC/Kinv), the load that has not been fed (Pdis) is calculated. The energy deficit should be compensated either by batteries or the AC generator to cover the AC load or DC load.

The second part selects operating modes of the power station. Each mode is represented by a single place: Mode0, Mode1, Mode2 and Mode3. Communication between operating modes is carried out by the transition SELECTED_MODE. The latter is triggered when it receives information from the first part, and the next node when the aforementioned mode is selected. Although transition SELECTED_MODE is enabled for all modes, it can drive only one mode for each hour. This situation is called a conflict (because the binding elements are enabled individually, but not synchronously), and it is said that the transition SELECTED_MODE is in conflict with itself. The switching between the modes is determined by evaluating the corresponding arc expression, associated to the output arcs from the places Mode0, Mode1, Mode2, Mode3, according to the rules described in Section. These transmit information to one of four transitions (PVswitchOFF, BatswitchON, PVswitchON, PVswitchON1). Together with the surrounding arc inscriptions, these transitions define how resources are reserved and released.

Table 1.

Conditions for selecting the appropriate operating mode.

\begin{tabular}{|c|c|c|}
\hline \multicolumn{2}{|c|}{ Conditions } & \multirow{2}{*}{$\begin{array}{l}\text { Selected } \\
\text { mode }\end{array}$} \\
\hline Charge/Discharge value & Battery States & \\
\hline Pch $=0.0$ and Pdis $>0.0$ & S1 & Mode 0 \\
\hline Pch $=0.0$ and Pdis $>0.0$ & S3 or S2 & Mode 1 \\
\hline Pch $>0.0$ and Pdis $=0.0$ & $\mathrm{~S} 2$ & Mode 2 \\
\hline$P c h>=0.0$ and $P$ dis $=0.0$ & S3 & Mode 3 \\
\hline
\end{tabular}

Due to limited space, the process shown in CPN Tools is not described in the paper. Figures 6 and 7 illustrate the performance of our strategy. Figure 6 shows markings of each place Mode0, Mode1, Mode2 and Mode3. The figure illustrates the decision made by the PN controller coordinating operating modes. According to the process, Figure 7 shows the power balance during the simulation and describes the evolution of the duty cycle for PV sources and batteries. The synchrony between consumption and photovoltaic generation can be considered to allow the direct use of energy. In this simulation, the weather was very sunny.

During the night, energy is supplied by batteries and the system is in mode 1. At 8 a.m. and 5 p.m. PV panels generate approximately $401 \mathrm{Wh}$ of power, which is insufficient. The batteries are used to compensate for the gap. At 9 a.m., when the power generated by the PV increases very rapidly and exceeds the load, the PN switches the system to mode 2 . Surplus power is stored in batteries, which are recharged. At 2 p.m., when batteries are full and surplus PV power can no longer be injected into batteries, the PN switches the system to mode 3 . In mode 3 the battery SOC is constant.

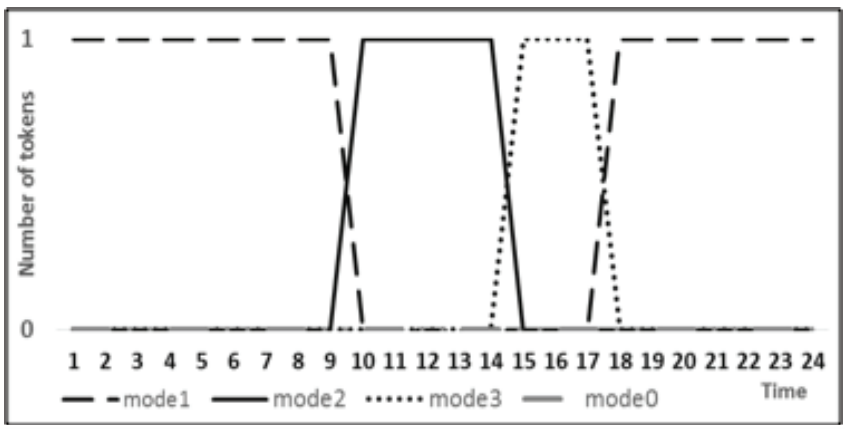

Figure 6.

Mode switches in function of time. 


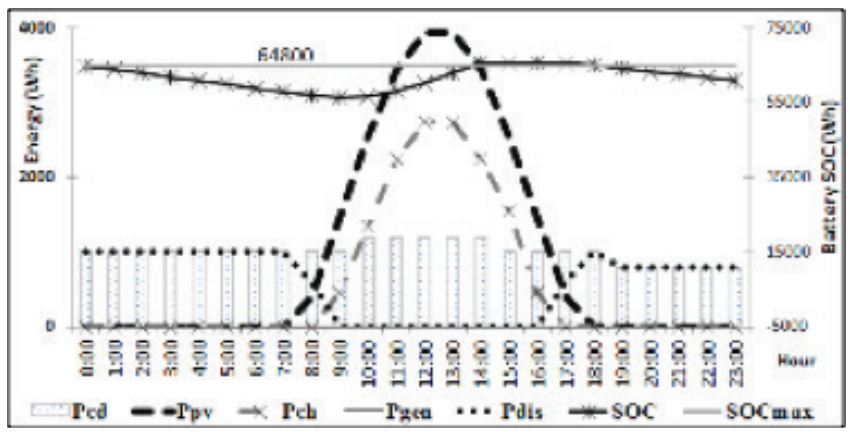

Figure 7.

Simulation results.

\section{OPTIMIZATION METHODOLOGY}

This research proposes a HOGA based-optimal design of PV-Diesel-Battery stand-alone hybrid energy system for a specific vessel. The system should be properly designed in terms of economic and environmental aspects that are affected by physical and operational constraints and strategies. HOGA software uses Genetic Algorithms (GA) that may produce adequate solutions when applied to highly complex problems (Dufo-Lopez, 2006; Dufo-Lopez and Bernal-Agustin, 2005; DufoLopez et al. 2007; Gudelj and Krčum, 2013). They optimize system components (main genetic algorithm) and the control strategy (secondary genetic algorithm (HOGA, 2017). The program permits mono or multi objective optimization (Dufo-Lopez and Bernal-Agustin, 2005). In this research, the focus of the analysis was on the multi-objective design of the hybrid PV-diesel system with battery storage, intended to minimize both the Net Present Cost (NPC) of the system and the life cycle of $\mathrm{CO}_{2}$ emissions (LCE), taking into account only emissions from fuel consumption. The NPC represents investment costs plus the discounted present values of all future costs during the system's lifetime. It can be defined as follows:

$N P C=\Sigma_{k}\left(C_{k}+C_{R E P}^{k}+C_{O \& M}^{k} \cdot \frac{1}{C F R(i r, R)}+C_{F}\right)$

where $C_{k}(\$)$ represents capital costs of each component $k$ (PV generator, battery, inverter, battery charge controller and diesel generator). $C_{R E P}^{k}(\$)$ indicates the cost of replacement of each component $k$ during the system's lifetime. $C_{Q \& M}^{k}(\$)$ are the annual operating and maintenance costs for component $k$ throughout the system's lifetime. CRF is capital recovery factor (Yang et al., 2008; RSoSPS, 2017) which is defined as follows:

CFR $(i r, R)=\frac{i r \cdot(1+i r)^{R}}{(1+i r)^{R}-1}$ where $R$ is the useful lifetime of the project, ir is the real interest rate, which is a function of the nominal interest rate $i r_{\text {nominal }}$ and the annual inflation rate $f_{r}$, defined by following equation (Yang et al., 2008):

$i r=\frac{i r_{\text {nominal }}-f_{r}}{1+f_{r}}$

$C_{F}(\$)$ are fuel consumption costs for $1 \mathrm{~h}$ of diesel generator operation (Belfkira et al, 2011):

$C_{F}=\operatorname{Pr}_{F} \cdot\left(A \cdot P_{D}+B \cdot P_{R D}\right)$

where $\operatorname{Pr}_{F}$ is fuel price $(\$ / \mathrm{I}), A=0.246 \mathrm{I} / \mathrm{kWh}$ and $\mathrm{B}=0.0845 \mathrm{I} / \mathrm{kWh}$ fuel curve coefficients.

The model of PV-Diesel-Battery stand-alone hybrid energy system for a specific vessel is a multi-objective problem where two objects are to be minimized (the sum of the net present cost and life cycle $\mathrm{CO}_{2}$ emissions) and is expressed as follows:

$\min F=\min [N P C(x), L C E(x)]$

$x=\left\{N_{P V^{\prime}}, a, N_{B A T^{\prime}}, b, N_{G}, c\right\}$

where $N_{P V^{\prime}}, N_{B A T}$, and $N_{G}$ are respectively the total number of PV panels, batteries and AC generators. $a, b$ and $c$ are the type of PV panel, the type of battery, the type of AC generator, respectively. Additional constraints to be imposed are:

$P_{P V}(t)+P_{B A T}(t)+P_{G}(t) \geq P_{\text {load }}(t)$

$S O C_{\min } \leq S O C(t) \leq S O C_{\max }$

$\left.\begin{array}{l}0 \leq N_{P V} \leq N_{P V \max } \\ 0 \leq N_{B A T} \leq N_{B A T \max }\end{array}\right\}$

Constraint (8) ensures that for any given period $t$, the total power supply from the hybrid generation system is sufficient to supply total demand. The relation (9) determines the maximum depth of battery discharging and the minimum depth of battery charging. The relation (10) is the constraint referring to the number of PV modules and batteries.

The number of batteries to be connected in a series is not subject to optimization but is a straightforward calculation, whereas the number of parallel battery strings $\mathrm{N}_{\mathrm{BAT}, \mathrm{P}}$, each consisting of $\mathrm{N}_{\mathrm{BAT}, \mathrm{S}}$ batteries connected in series, is a design 
variable that needs optimization (Trazouei and Trazouei, 2013). The total number of batteries is $N_{B A T}=N_{B A T, P} * N_{B A T, S}$.

The number of panels to be connected in series $N_{P V, S}$ depends on the selected DC bus voltage (bus V) and is not subject to optimization. The number of parallel strings $\mathrm{N}_{\mathrm{PV}, \mathrm{P}}$ is the design variable that needs optimization. The total number of PV panels is $N_{P V}=N_{P V, P} * N_{P V, S}$.

Inputs required for system optimization include capital expenses, replacement, operating and maintenance costs of all components, as well as efficiency, components and project lifetime, component specifications, hourly load demand and hourly meteorological data over a one year period.

\section{EXAMPLE OF APPLICATION}

HOGA was used as a test tool for the optimization of the hybrid system analyzed in this research. As mentioned above, the PV-Diesel-Battery energy system on the special-purpose vessel serving along the eastern Adriatic coast is used as case study. The system has the DC voltage of $48 \mathrm{~V}$ and $A C$ voltage of $230 \mathrm{~V}$. The typical daily load profiles of the ship are shown in Figure 8.

The selection of appropriate solar panels requires data on solar radiation by month in the given area. An average monthly solar irradiation energy throughout the year for the eastern Adriatic Coast is between $1.62\left(\mathrm{kWh} / \mathrm{m}^{2}\right)$ in December and $8.07\left(\mathrm{kWh} / \mathrm{m}^{2}\right)$ in July. In this area, the value of average daily irradiation on horizontal surface is $4.76\left(\mathrm{kWh} / \mathrm{m}^{2} /\right.$ day). Therefore, the potential for the utilization of this type of energy is clearly rather high.

In optimizations, commercially available components are considered and prices are all unfeigned. Most low budget solar
PV panels are designed for use in residential applications and will not survive being installed on a vessel or seawater exposure which will cause them to delaminate, corrode or deteriorate. KYOCERA Solar panels (Kyocera, 2017) have demonstrated successful and reliable performance in the marine environment over the years. This is the reason why three commercial models of multi-crystalline silicon KCM solar panels of 140/255/320 Wp, featuring 12/12/24 V nominal voltage, having the acquisition cost of 293/317/432 $\$ /$ per panel and the annual O\&M cost of 2.93/3.17/4.32 \$/year, respectively, are considered. As the DC voltage of the system is $48 \mathrm{~V}$, the application of four or two panels in series is possible, depending on the nominal voltage (48/nominal voltage). The number of parallel groups allowed ranges between 0 and 20. The estimated lifetime of PV arrays is 25 years and emissions are $600 / 600 / 800 \mathrm{kgCO}_{2}$, respectively, in the manufacturing.

Trojan's deep-cycle flooded batteries were chosen. Trojan's technology has proven to be suitable for use in marine applications (The Marine battery..., 2015). Three models of $12 \mathrm{~V}$ batteries with the capacity of $97 / 106 / 225$ Ah, having the acquisition cost of 150/195/211.6\$/battery, respectively, are considered. As the DC voltage of the system is $48 \mathrm{~V}$, there are four batteries in series. The number of parallel groups allowed ranges between 1 and 15. The O\&M cost amounts to 1.5/1.95/1.6\$/year.

The number of possible AC generators in parallel can range from 1 to 3 . The lifetime of an AC generator is $10000 \mathrm{~h}$, and its minimum $A C$ generator output power is $30 \%$. $\mathrm{CO}_{2}$ emission is $3.5 \mathrm{~kg} \mathrm{CO}$. The effective interest rate considered is $6 \%$. The fuel price is $0.8 € / \mathrm{l}$. The efficiencies are $80 \%$ for the batteries, $90 \%$ for the inverter and $90 \%$ for the battery charger. The lifetime of the entire system is 25 years.

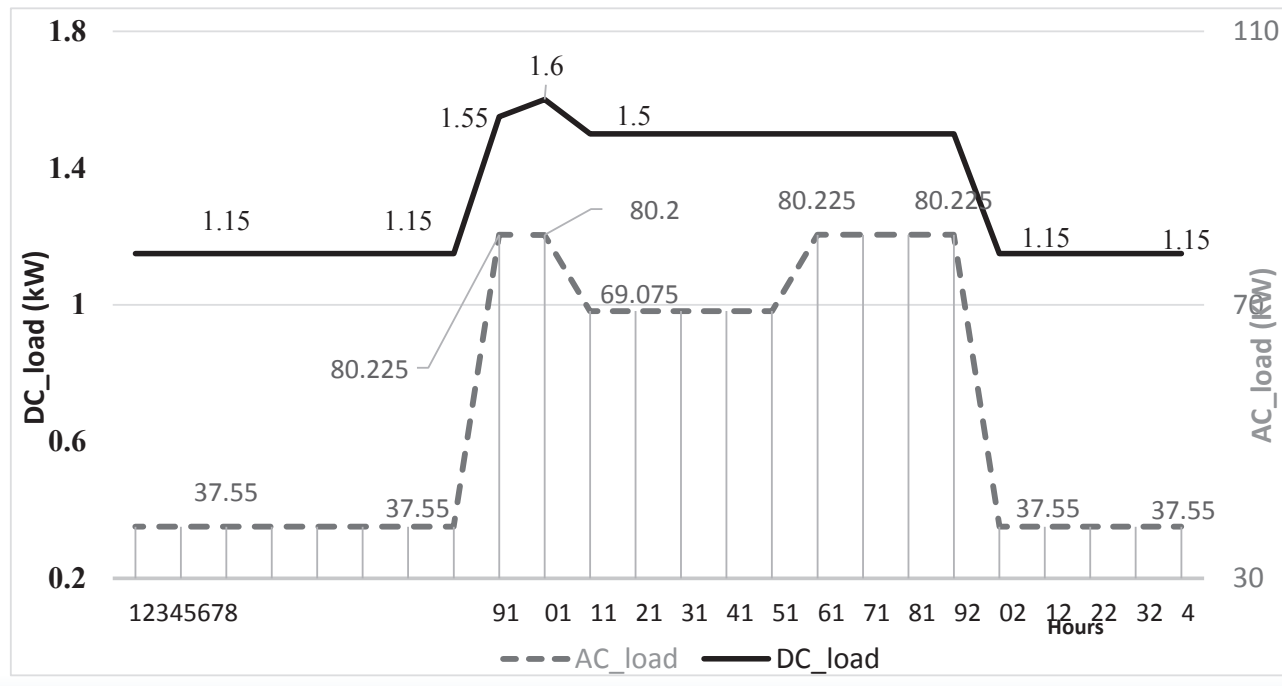

Figure 8.

Average hourly distribution of AC and DC loads. 


\section{OPTIMIZATION RESULTS}

This section is an assessment of the realistic operating scenario for PLOVPUT's working boat. The behavior of the energy storage and production system was simulated using the simulator presented in the preceding section. Three load profiles were tested: profile \#1: full AC/DC load was simulated; profile \#2: $10 \%$ of AC load and full DC load were simulated; profile \#3: only DC load was simulated.

The goal of optimization is to find an optimal configuration of the system by simultaneously minimizing net present cost and $\mathrm{CO}_{2}$ emissions in terms of the decision variables of the problem (Eq. 7). This task was achieved using HOGA, utilizing a multiobjective genetic algorithm.

The applied genetic algorithm GA can search for the configuration of PV panels, batteries and AC generators that minimizes the two objectives expressed in Equation (6). The genetic algorithm GA simulates the survival of the fittest among individuals over consecutive generations throughout the solution of a problem (Goldberg, 1989). Each generation consists of a population analogous to a set of chromosomes. In this paper, GA uses an integer representation of chromosomes. Each chromosome is a vector in the form $\left[\begin{array}{llllll}N_{P V} & a & N_{B A T} & b & N_{G} & c\end{array}\right]$ that consists of six positions which, respectively, correspond to six decision variables: number of PV panels, the type of PV panel, the number of batteries, the type of battery, the number of $A C$ generators and the type of $A C$ generator (Eq. 7). The individuals in the population are then exposed to the process of evolution. The elitist mechanism is applied which keeps individuals with high degree of adaptability depending on their fitness. Crossover operator is applied to the group, and individuals are selected by crossover and mutation probability to generate new individuals. Thus, genes from good individuals propagate throughout the population and each subsequent generation achieves better fitness values.

The parameters for the Genetic Algorithm (GA) have been taken from Table 2.
Table 2.

Multi-objective GA Parameters.

\begin{tabular}{llll} 
Parameter & Values & Parameters & Values \\
\hline $\begin{array}{l}\text { Population } \\
\text { Size }\end{array}$ & 15 & $\begin{array}{l}\text { Selection } \\
\text { function }\end{array}$ & Elitism \\
\hline $\begin{array}{l}\text { Population } \\
\text { Type }\end{array}$ & vector & $\begin{array}{l}\text { Crossover } \\
\text { function }\end{array}$ & Single-point \\
\hline $\begin{array}{l}\text { Initial } \\
\text { Population }\end{array}$ & random & $\begin{array}{l}\text { Crossover } \\
\text { rate }\end{array}$ & 0.75 \\
\hline $\begin{array}{l}\text { Max } \\
\text { generation }\end{array}$ & 20 & $\begin{array}{l}\text { Mutation } \\
\text { function }\end{array}$ & Uniform \\
\hline & & Mutation rate & 0.01 \\
\hline
\end{tabular}

The obtained optimal configuration for profile \#1 is unacceptable because it includes a large number of PV modules which cover an area of $120 \mathrm{~m} 2$.

The obtained optimal configuration for profiles \#2 and \#3 has the lowest system total cost and the lowest emissions. According to the results, the lowest NPC over 25 years is obtained when PV-diesel hybrid generation is combined with battery storage. In addition, this configuration is capable of meeting the load demand without any unmet load during simulation time. Hybrid solutions for renewable and $A C$ generation can reduce costs in the long term, although the initial investment is much higher. The use of AC generator is substantially reduced, resulting in fuel economy and emission savings (see Table 2). Figure 9 and Figure 10 show optimal configurations for load profiles \#2 and $\# 3$, total energy production for each component and hourly simulation throughout the year.

During the year, for load profile \#2, AC generators produce about $77.7 \%$ and renewable resources only $22.3 \%$ of the overall energy. For profile \#3, owing to lower load (DC load only), a viable solution is an AC generator operating only for a couple of hours each day. The AC generator produces only $0.01 \%$ of the energy,

Table 3.

Multi-objective GA Parameters.

\begin{tabular}{|c|c|c|c|c|c|c|c|c|c|}
\hline \multirow{2}{*}{$\begin{array}{l}\text { Load } \\
\text { profile }\end{array}$} & \multicolumn{2}{|c|}{ Only Diesel } & \multicolumn{7}{|c|}{ Optimal results } \\
\hline & $\begin{array}{l}\text { NPC } \\
\text { (\$) }\end{array}$ & $\begin{array}{l}\text { AC operation } \\
\text { (h/yr) }\end{array}$ & $\begin{array}{l}\mathrm{CO}_{2} \\
\text { (t/yr) }\end{array}$ & $\begin{array}{l}\mathrm{AC}_{-} \mathrm{CO}_{2} \\
(\mathrm{t} / \mathrm{yr})\end{array}$ & $\begin{array}{l}\text { NPC } \\
\text { (\$) }\end{array}$ & $\begin{array}{l}\text { PV power } \\
\text { (W) }\end{array}$ & $\begin{array}{l}\text { Battery capac. } \\
\text { (Ah) }\end{array}$ & $\begin{array}{l}\text { AC Pgen_min } \\
\text { (kVA) }\end{array}$ & $\begin{array}{l}\text { AC operation } \\
\text { (h/yr) }\end{array}$ \\
\hline$\# 1$ & - & - & 622.56 & 595.52 & 3809600.0 & $450 \times 255$ & $270 \times 225$ & 57 & 5127 \\
\hline$\# 2$ & 272261 & 6852.4 & 56.32 & 54.12 & 699016.88 & $45 \times 255$ & $72 \times 225$ & 3 & 4818 \\
\hline \#3 & 63034 & 4376.3 & 0.774 & 10.00 & 49809.00 & $28 \times 320$ & $24 \times 225$ & 3 & 2 \\
\hline
\end{tabular}


while renewable resources produce the remaining $99.9 \% . \mathrm{CO}_{2}$ emissions from fuel combustion are avoided, leaving only those relating to the life cycle of the facility (manufacturing, transport and scrapping). However, the AC generator remains an important source of energy meeting the AC load demand although its O\&M cost is high.
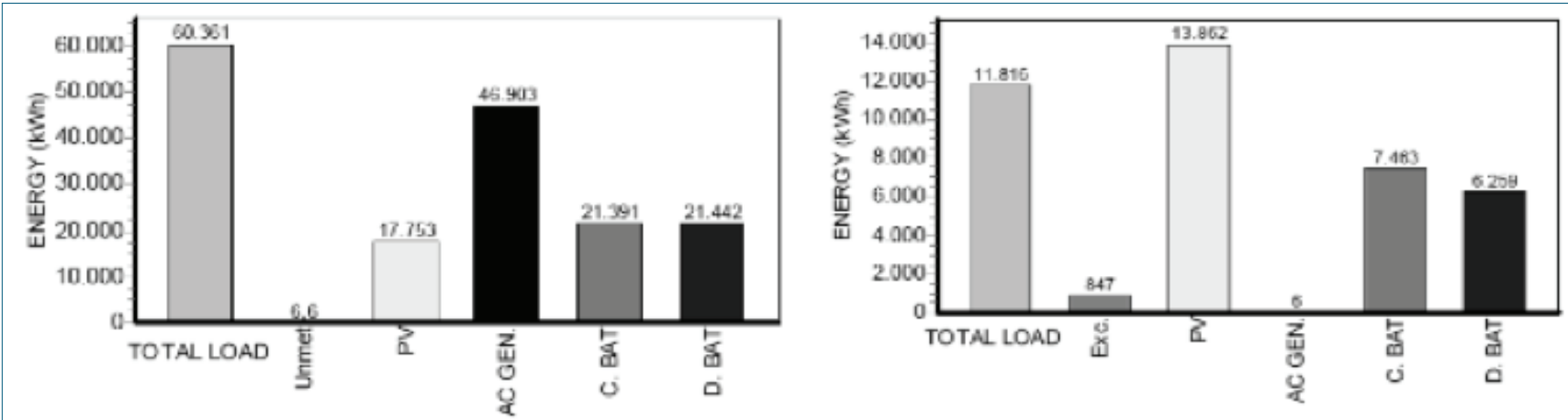

Figure 9.

Energy during one year, load profiles \#2 and \#3.

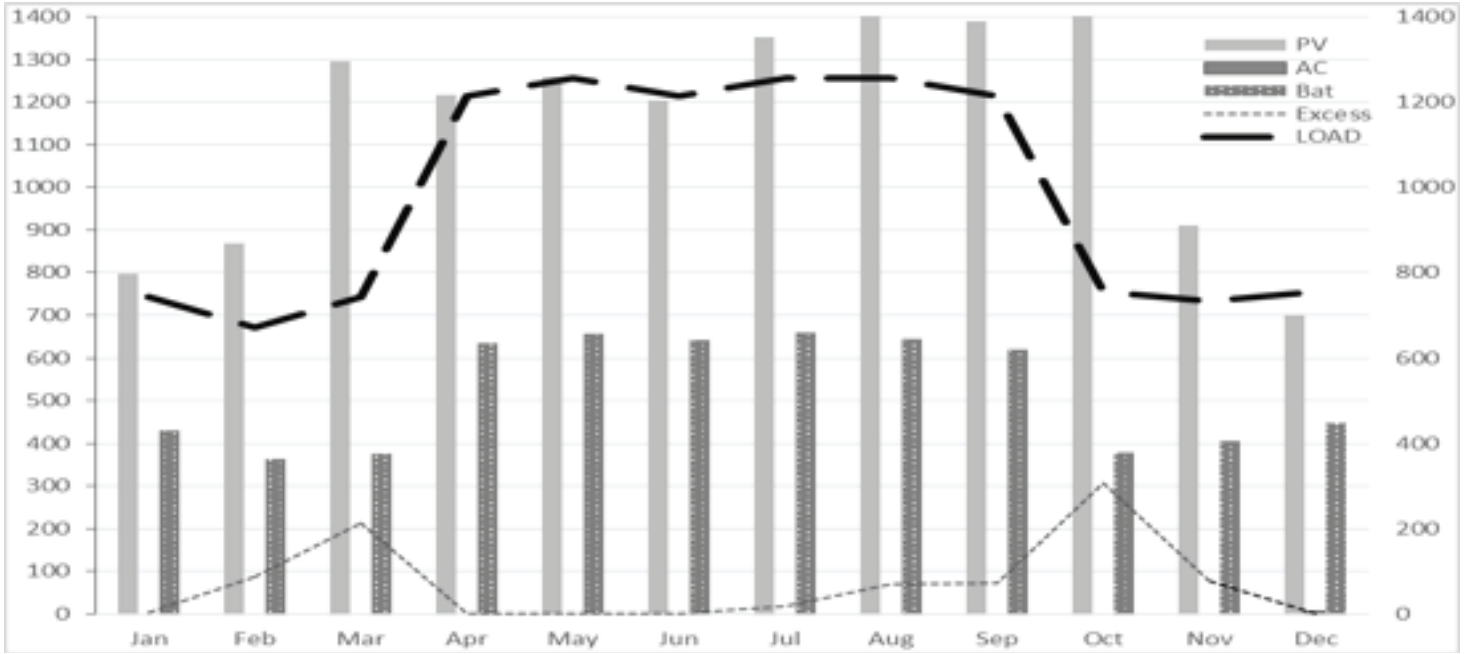

Figure 10

Daily average energy to comply with the operational profiles and excess energy, profile \#3.

\section{CONCLUSION}

The goal of this research was to prove that a specific vessel, a workboat built in 2016 and operated by Plovput, may generate renewable energy in compliance with the rules of the International Maritime Organization (IMO), which are becoming mandatory as of 2025. The use of photovoltaic (PV) solar systems to supply various onboard users with power (e.g. instruments, lights, winches, propulsion...) reduces fossil fuel consumption and consequently the harmful exhaust gas emissions. However, the efficient application of solar energy onboard ships depends on investment costs of any given solar system and the careful consideration of a number of factors such as required loads and the availability of solar energy. Using a simulation model that only considered PV systems which can actually be mounted on the deck of Plovput's vessel, the consumption loads in certain modes of vessel operation were monitored, and the information flow followed to manage the distribution of load power. The optimal design, allowing energy management, operational cost function minimization and the reduction of $\mathrm{CO}_{2}$ emission, was implemented using the HOGA software.

This paper focuses on information management coordination and energy distribution that contribute to the study and represent a contribution to meeting IMO recommendations. 
It is a part of the authors' ongoing study and can be used for further research that can be applied to similar vessels. The study can easily be extended to include considerations and other renewable energy sources suitable for onboard applications.

\section{REFERENCES}

$3^{\text {rd }}$ IMO GHG study, (2017), available at: http://www.Imo.Org/En/Ourwork/ Environment/Pollutionprevention/Airpollution/Pages/Greenhouse-GasStudies-2014.aspx [accessed 14 October 2017.].

Belfkira, R., Zhang, L., and Barakat, G., (2011), Optimal Sizing study of hybrid wind/ PV/diesel power generation system. Solar Energy 85(1), pp. 100-110., available at: https://doi.org/10.1016/j.solener.2010.10.018

CPNTools, (2017), available at: http://www.daimi.au.dk/CPnets/ [accessed 14 October 2017.].

Dufo-López, R., Bernal-Agustín, J.L. and Rivas-Ascaso, D. M., (2006), Design of Isolated Hybrid Systems Minimizing Costs and Pollutant Emissions, Journal of renewable energy 31(14), pp. 2227-2244., available at: https://doi.org/10.1016/j.renene.2005.11.002

Dufo-López, R. and Bernal-Agustín, J.L., (2005), Design and control strategies of PVDiesel systems using genetic algorithms, Solar Energy 79(1), pp. 33-46., available at: https://doi.org/10.1016/j.solener.2004.10.004

Dufo-López, R., Bernal-Agustín, J.L. and Contreras, J., (2007), Optimization of Control Strategies for Stand-Alone Renewable Energy Systems with Hydrogen Storage, Journal of Solar Energy 32(7), pp. 1102-1126., available at: https://doi.org/10.1016/j.renene.2006.04.013

Goldberg, D.E., (1989), Genetic Algorithms in Search Optimization and Machine Learning, Addison-Wesley Longman

Gudelj, A., Kezić, D., and Vidačić, S., (2012), Marine Traffic Optimization Using Petri Net and Genetic Algorithm, PROMET - Traffic \& Transportation 24(6), pp. 469-478., available at:

https://doi.org/10.7307/ptt.v24i6.1199

Gudelj A. and Krčum M., (2013), Simulation and Optimization of Independent Renewable Energy Hybrid System, Transactions on Maritime Science 2(1), pp. 2835., available at:

https://doi.org/10.7225/toms.v02.n01.004

HOGA, (2017), available at: http://www.unizar.es/rdufo.hoga-eng.htm [accessed 14 October 2017.].
Kyoto Protocol Introduction, (2017), available at: http://unfccc.int/kyoto_protocol/ items/2830.php [accessed 14 October 2017.].

Energy Efficiency Design Index - IMO, (2012), http://www.imo.org/en/MediaCentre/ HotTopics/GHG/Pages/EEDI.aspx [accessed 14 October 2017.].

Real-time Simulation of Shipboard Power System, (2017), available at: http://www. opalrt.com/sites/default/files/technical_papers/REALTIME \%20SIMULATION \%20OF \%20SHIPBOARD \%20POWER \%20SYSTEM.pdf [accessed 14 October 2017.].

The marine battery and LiFePO4 battery chemistry, (2015), available at: https:// batterybro.com/blogs/18650-wholesale-battery-reviews/34311235-the-marinebattery-and-the-lifepo4-battery-chemistry [accessed 14 October 2017.].

Øverleir, M.A., (2015), Hybridization of General Cargo Ships to meet the Required Energy Efficiency Design Index, available at: https://brage.bibsys.no/xmlui/ handle/11250/2350857 [accessed 14 October 2017.].

Kyocera Solar PV Panels, (2017), available at: https://www.emarineinc.com/ categories/Kyocera-Solar-PV-Panels [accessed 14 October 2017.].

International Maritime Organization, available at: https://www.imo.org [accessed 14 October 2017.].

Jensen K, Kristensen, L.M., and Wells, L., (2007), Colored Petri Nets and CPN Tools for Modelling and Validation of Concurrent Systems, International Journal on Software Tools for Technology Transfer (STTT), pp. 213-254., available at:

https://doi.org/10.1007/s10009-007-0038-x

Jensen, K., (1991), Colored Petri Nets: A high-level Language for System Design and Analysis, High-level Petri Nets, pp. 44-119., available at: https://doi.org/10.1007/978-3-642-84524-6_2

Krčum M., Gudelj A., and Žižić, L., (2010), Marine Applications for Fuel Cell Technology, Proceedings of the International Conference of Transport System (ICTS), Portorož: Slovenia.

Technical documentation of the PLOVPUT company's working boat.

Trazouei, S.L., Tarazouei, F.L., (2013), Optimal Design of a Hybrid Solar-Wind-Diesel Power System for Rural Electrification Using Imperialist Competitive Algorithm, International Journal of Renewable ENERGY Research, 3(2), pp. 403-411.

Yang, H., Zhou, W., and Fang, Z., (2008), Optimal sizing method for stand-alone hybrid solar-wind system with LPSP technology by using genetic algorithm, Sol Energy 82(4), pp. 354-367., available at: https://doi.org/10.1016/j.solener.2007.08.005 